OPEN ACCESS

Edited by:

Medhat M. Osman,

Saint Louis University,

United States

Reviewed by:

Nghi Co Nguyen,

University of Pittsburgh,

United States

Mustafa Erkan Altinyay,

Acıbadem Bodrum Hospital, Turkey

*Correspondence:

Yael Bar

yael.b@ttvmc.gov.il

Specialty section:

This article was submitted to Cancer Imaging and Diagnosis, a section of the journal

Frontiers in Oncology

Received: 28 April 2017 Accepted: 07 June 2017 Published: 26 June 2017

Citation:

Bar Y and Merimsky O (2017)

Soft-Tissue Sarcoma following

Traumatic Injury: Case Report and

Review of the Literature.

Front. Oncol. 7:134.

doi: 10.3389/fonc.2017.00134

\section{Soft-Tissue Sarcoma following Traumatic Injury: Case Report and Review of the Literature}

\author{
Yael Bar* and Ofer Merimsky \\ Oncology Division, Tel Aviv Sourasky Medical Center, Affiliated with Sackler Faculty of Medicine, Tel Aviv University, \\ Tel Aviv, Israel
}

Soft-tissue sarcomas (STSs) are a heterogeneous group of tumors, which accounts for $1-2 \%$ of adult cancers worldwide. Despite quite a few reports on traumatic events followed by STS formation, the link between the two events remains a point of controversy. In this paper, we present the case of a young patient who had a rhabdomyosarcoma in the lower extremity, which had developed in the same location where the patient was wounded by a gunshot 9 years earlier. X-ray and CT scans clearly showed metal fragments in the area of sarcoma formation. The patient underwent neoadjuvant chemotherapy treatment, to which the tumor was, unfortunately, unresponsive. Therefore, the patient was referred to below-knee amputation of the injured leg. There are several possible etiological factors for sarcoma development in this patient, including tissue damage and inflammation, as well as the presence of metal fragments in the tissue and the limb's exposure to radiation during multiple imaging tests. Here, we will discuss the potential influence wielded by the injury itself, as well as its complications and its medical management on the formation of the sarcoma, in light of the current literature.

Keywords: injury, wound, soft-tissue sarcoma, rhabdomyosarcoma, metal fragments, radiation, inflammation

\section{INTRODUCTION}

Soft-tissue sarcomas (STSs) represent a heterogeneous mix of more than 50 mesenchymal types of tumors, which, altogether, encompass approximately $1-2 \%$ of adult cancers worldwide $(1,2)$. The question of whether trauma can cause malignancy in general and sarcoma, in particular, has been preoccupying researchers since the late eighteenth century (3). Nevertheless, despite quite a few reports in the last 100 years on traumatic events followed by STS formation (4-6), the causative relation between the two events remains a point of controversy. Recent works in lab animals show a causative connection between acute tissue injury and sarcoma formation $(7,8)$.

In this work, we present a case of a young patient with Rhabdomyosarcoma in the lower extremity, who had developed in the same location where the patient was injured by a gunshot 9 years prior. We discuss the potential influence of the injury, its complications, and its medical management on sarcoma formation, in light of the current literature.

\section{CASE REPORT}

A 31-year-old patient was diagnosed with rhabdomyosarcoma of the right calf. Nine years earlier, while in active military service, he was injured by a gunshot wound. Three bullets hit his stomach 
and led to the destruction of the left kidney, a perforation of the small intestine, and damage to soft tissue in the retroperitoneum. Two more bullets struck the right calf and the right ankle. After he was intubated, an urgent abdominal surgery was performed, which included the removal of the injured kidney. In addition, the patient underwent external fixation of the right fibula and tibia. He was then transferred to the intensive care unit for further treatment.

After a month, the patient underwent skin grafting in the area of the gunshot wounds on the right calf and right ankle. Then, the patient was transferred to a rehabilitative department in another hospital. After 2 months, a conversion surgery from external fixation to internal fixation was performed on the right leg. Later, due to an infection of the wound in the right ankle, the patient was treated with antibiotics for 6 weeks and then, due to the continuation of the infection, an additional procedure was performed for the removal of metal fragments from the right ankle. It should be noted that during his hospitalization and follow-up period, the patient underwent dozens of imaging tests for the injured leg, including X-rays, CT scans, and skeletal scans. X-ray and CT scans of the right leg, which were performed for surveillance purposes 1 and 3 years following the injury, clearly indicate the presence of remaining metal fragments, which were not removed during the surgical procedures (Figure 1).
Nine years following the injury, the patient began to notice a bulge in the area of the surgical scar in the right posterior calf (Figure 2). The patient was referred to a biopsy from the mass and the pathology indicated pleomorphic rhabdomyosarcoma. A FDGPET-CT indicated a mass in the right calf, another hypermetabolic area near the right ankle; an area of former prolonged infection, and no clear-distance metastatic spread (Figure 3). An X-ray clearly showed metal fragments in the area of the sarcoma in the right calf (Figure 4). Following a multidisciplinary discussion, the patient was referred to neoadjuvant treatment with VAC-IE chemotherapy regiment. A FDG-PET-CT preformed after two chemotherapy cycles indicated that the tumor had no response to the treatment. Hence, the patient was referred to below-knee amputation of the right leg.

\section{DISCUSSION}

The presented case raises the possibility that there is a connection between sarcoma development and tissue injury, 9 years apart in the same location. If this type of connection exists, it is likely derived from combination of several etiological factors: (a) tissue damage and the regenerative and inflammatory processes following it; (b) the presence of metal fragments in the tissue; and (c) radiation to the limb by multiple imaging tests. Below, we review the current knowledge regarding each of these factors.
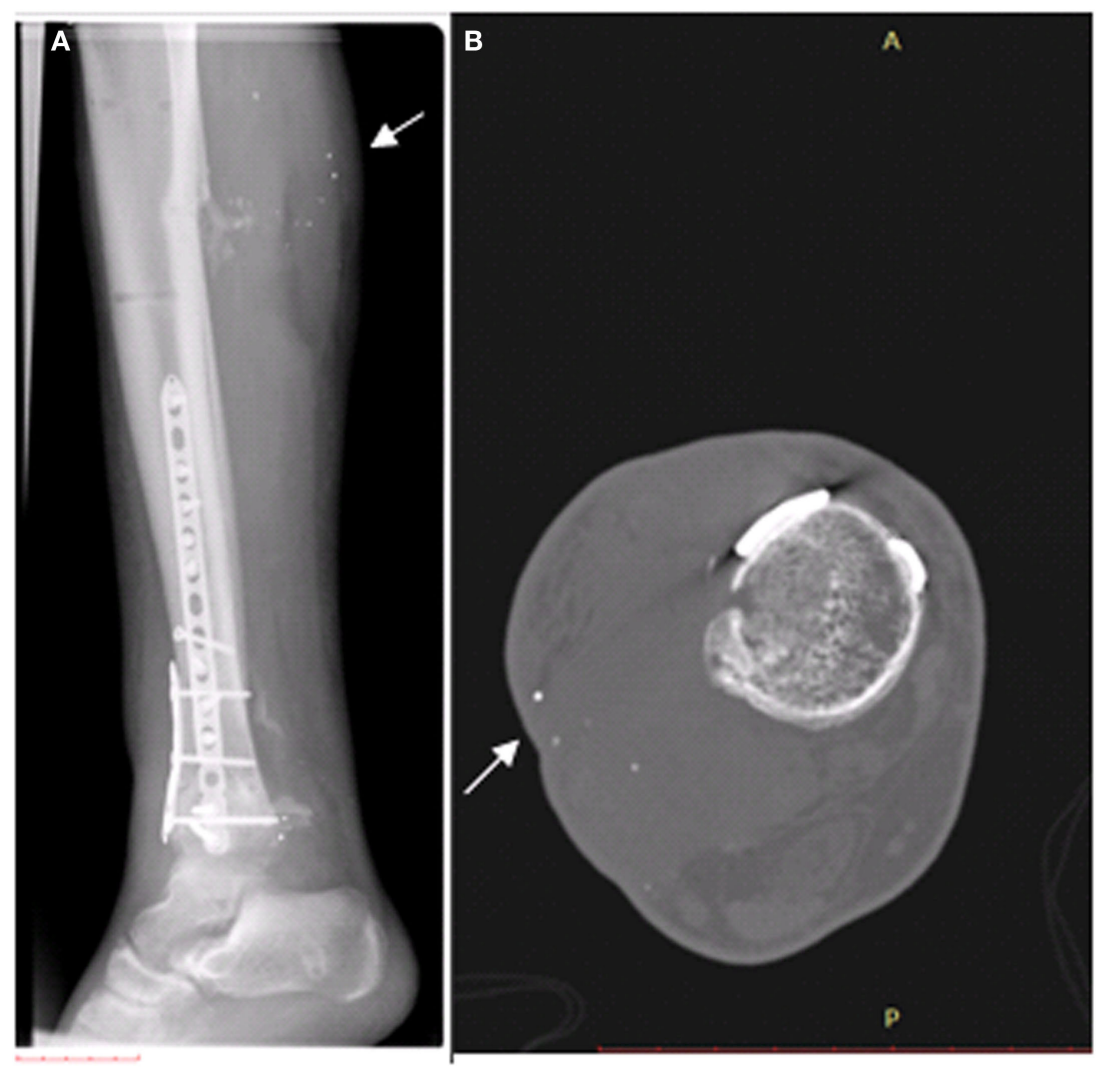

FIGURE 1 | Existence of metal fragments (white arrows), which were not removed during the surgical procedures, in the right calf. (A) X-ray preformed 1 year after the injury. (B) CT scan preformed 3 years after the injury. 
There are quite a few reports of STS formation following traumatic injury, surgical or other (4-6). Nevertheless, there is a great challenge in confirming a causative relation between the two events. This is partially due to the fact that trauma often draws attention to an already existing mass in the same location. There have been several studies conducted on lab animals that indicated a direct connection between tissue injury and sarcoma formation. Several subsequent works showed that injection of

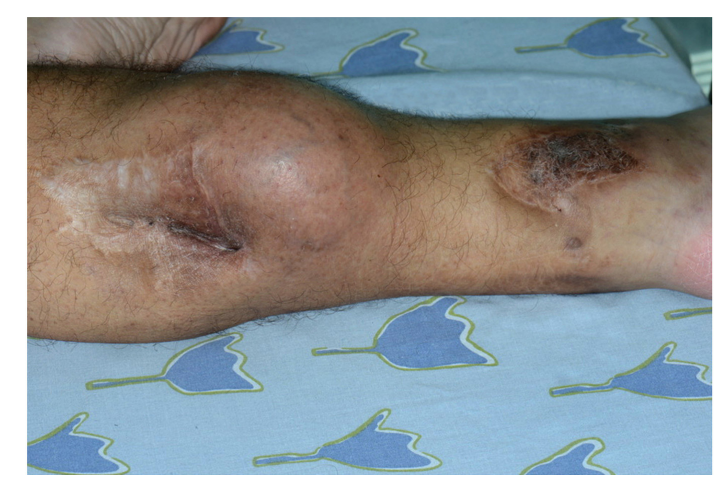

FIGURE 2 | Neoplastic mass next to a shotgun wound scar in the calf (left). Additional shotgun wound scar in the ankle (right).
Rous sarcoma virus to chickens resulted in sarcoma development uniquely at the virus injection site in the wing, or in the contralateral wing, after being wounded with a clip. Interestingly, no other tumors were found distant from those sites, despite the systemic presence of the virus in the blood (9-11). Similarly, transgenic mice constitutively overexpressing the $\mathrm{V}$-jun oncogene showed sarcoma formation only at the site of ear tagging and tail clipping (12-14). Transforming growth factor $\beta$, an inflammatory growth factor implicated in wound healing, can replace wounding in tumor development in Rous sarcoma virus-infected chicks. Contrastingly, the development of these wound tumors was inhibited by using $\beta$-methylprednisolone, an anti-inflammatory drug (11). These results emphasize the role of inflammation and cytokines release in the development of wound tumors. More recently, three published works investigated the connection between direct muscle injury and sarcogenesis in mice that have a genetic predisposition for sarcoma formation. First, Camboni et al. showed that cardiotoxin-induced muscle injury leads to STS formation at the site of injury in p53-null mice (7). In additional work, efforts to generate urothelial tumors in a mouse model harboring kRAS inducible activation, and loss of p53, resulted in STS development at the site of the suture (15). Finally, Van Mater et al. showed that muscle injury by cardiotoxin following specific P53 shutdown and kRAS activation in muscle PAX7+ cells cause accelerated sarcoma formation at the site of injury. Interestingly, no tumor developed when using cardiotoxin injection alone.
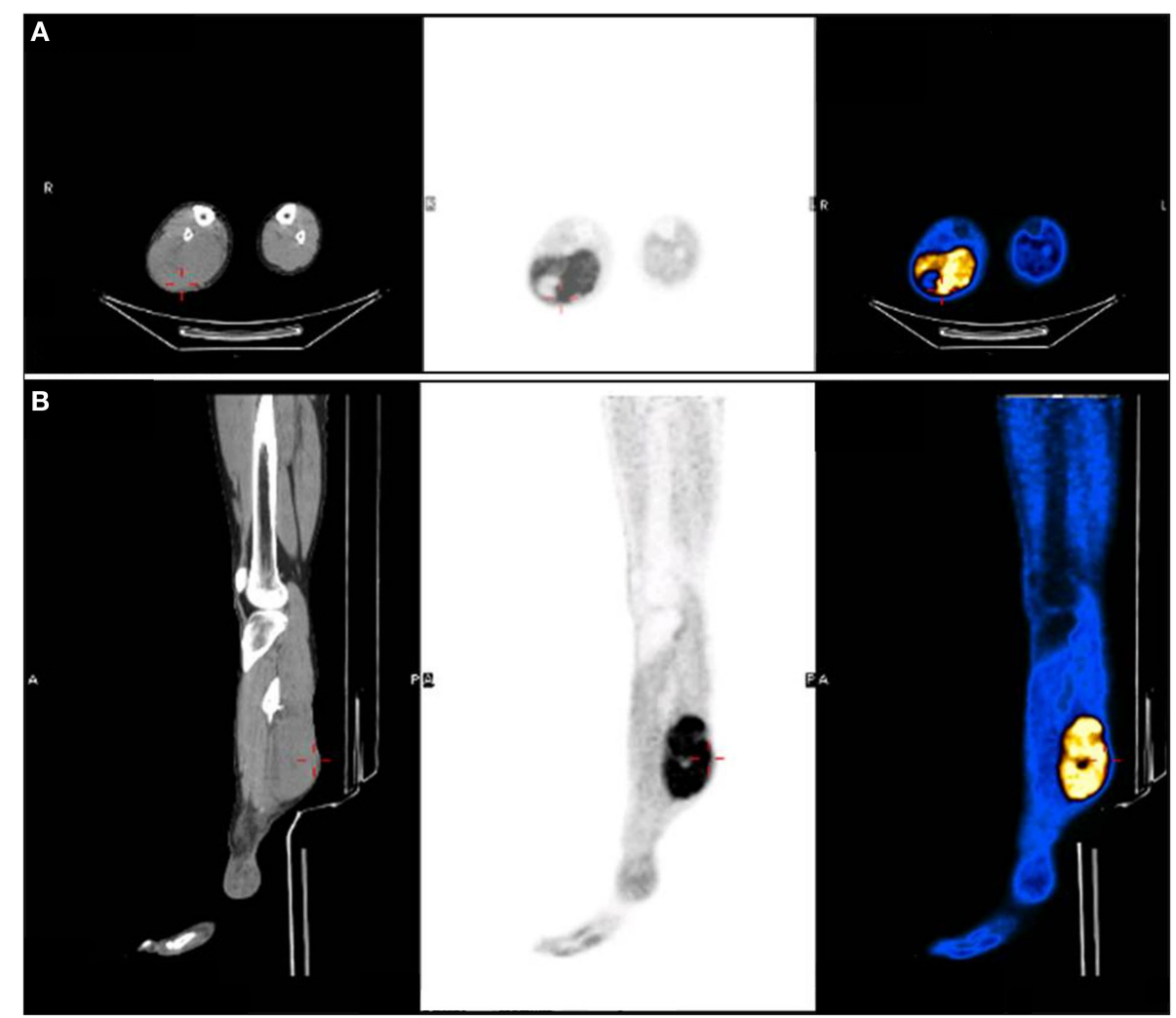

FIGURE 3 | FDG-PET-CT indicated a hypermetabolic mass in the right calf. (A) Axial view. (B) Sagittal view. 


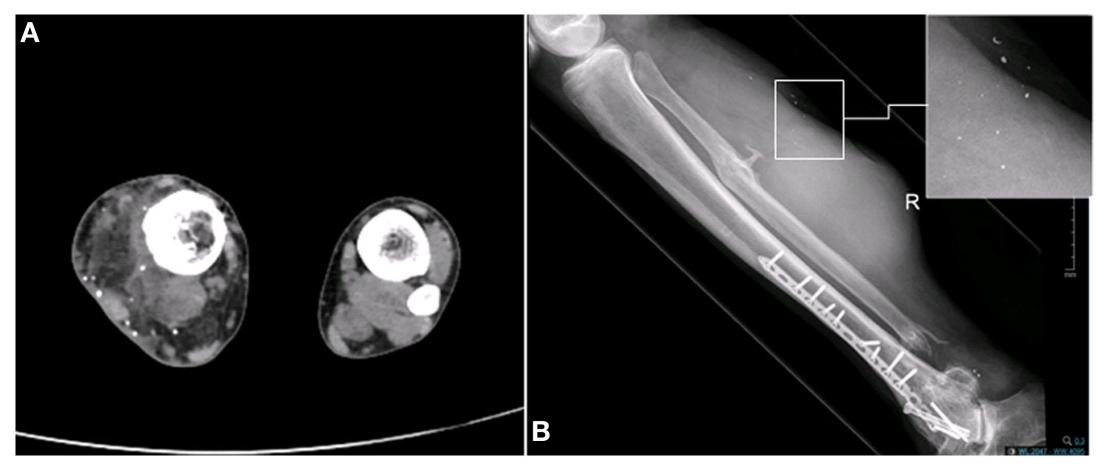

FIGURE 4 | Existence of metal fragments in the area of the sarcoma in the right calf. (A) CT scan. (B) X-ray.

Hence, the authors propose an initiator/promoter model, whereby injury acts as the promoter to drive sarcoma formation after the initiating genetic insult (8).

The link between tissue injury and sarcoma formation could be derived from the known link between inflammation and tumorigenesis (16-19). It is known that wound healing response to injury, triggers functional and phenotypic changes in fibroblasts, lymphocytes, epithelial, and endothelial cells. This is a dynamic process that consists of an inflammatory phase followed by epithelial cell proliferation and tissue remodeling $(20,21)$. Failure to exit the inflammatory stage results in improper tissue remodeling and chronic inflammation. Chronic inflammation and the secretion of inflammatory mediators by inflammatory cells (cytokines, chemokines, and growth factors) has been linked to tumorigenesis, tumor progression, and metastasis in many different cancers $(16,17,19)$ including sarcomas $(22)$.

During the treatment to the injured leg, the presented patient underwent multiple imaging examinations, including X-ray, CT, and bone scans. There is a well-established causative connection between radiation exposure and STS. STSs are one of the most common types of radiation-associated cancers in the general population (23-26). The median interval between radiotherapy and development of a radiation-associated sarcoma is about 10 years (27). This interval varied significantly by histologic type. Undifferentiated pleomorphic sarcomas constitute the most common type of radiation-induced sarcoma. Though uncommon, radiation-induced sarcomas usually have a poor prognosis (27). The molecular mechanisms of radiation-associated sarcomas are poorly understood (28).

The injured leg CT and X-ray images clearly show metal fragments in the area of the developing mass (Figure 4). Several works showed a connection between the presence of metal fragments in the tissue and sarcogenesis. Triggered by the usage of depleted uranium (DU) in the Gulf War, a work by Hahn et al. checked the carcinogenicity of DU metal in the muscle tissue of rats. In this work, DU particles cause localized proliferative reactions and formation of STS. The mechanism by which DU particles induced sarcomas is uncertain; however, the authors suggested that the corrosion of the particles in the tissue and the inflammatory response to the particles might lead to sarcoma formation (29). The composition of the bullets has changed over the years and now includes other metals such as tungsten, nickel, cobalt, and iron instead of uranium. Implantation of pellets containing tungsten, nickel and cobalt, into the quadriceps muscle of mice led to the development of a rhabdomyosarcoma around the pellet (30). Similarly, when implanted into the leg muscle of F344 rats, tungsten/nickel/cobalt pellets were found to induce highly aggressive metastatic rhabdomyosarcomas within 6-12 months $(31,32)$. Progressive corrosion of the pellets was clearly observed by electron microscopy. A microarray gene analysis of the tumors compared to normal muscle, revealed significant upregulation of cell cycle-associated genes as well as significant downregulation of muscle development and differentiation associated genes (32). Interestingly, the histological features of the sarcomas developed in rats following pellets implantation (31), high-grade pleomorphic rhabdomyosarcoma, was similar to the histological features of our patient's sarcoma.

\section{CONCLUSION}

The case presented above suggests the existence of a link between gunshot injury and the development of STS at the same location 9 years later. Although there are previous reports on sarcoma formation following trauma, this work places an emphasis on the different aspects of the traumatic event that can lead to sarcoma formation. This includes the injury itself, as well as the regenerative and inflammatory processes it entails, alongside its related complications and, of equal importance-its medical management and treatment. More work is needed to establish the connection between traumatic injury and STS formation and to determine the biological processes underline this phenomenon.

\section{ETHICS STATEMENT}

We confirm that the patient gave written informed consent for the publication of the report and for the publication of the picture presented in Figure 2.

\section{AUTHOR CONTRIBUTIONS}

OM: treated the patient. YB: wrote the paper and reviewed the literature. 


\section{REFERENCES}

1. Jo VY, Fletcher CD. WHO classification of soft tissue tumours: an update based on the 2013 (4th) edition. Pathology (2014) 46(2):95-104. doi:10.1097/ PAT.0000000000000050

2. Ng VY, Scharschmidt TJ, Mayerson JL, Fisher JL. Incidence and survival in sarcoma in the United States: a focus on musculoskeletal lesions. Anticancer Res (2013) 33(6):2597-604.

3. Coley WB II. The influence of injury upon the development of sarcoma. Ann Surg (1898) 27(3):259-84.

4. Coley WB, Higinbotham NL. Injury as a causative factor in the development of malignant tumors. Ann Surg (1933) 98(6):991-1012. doi:10.1097/ 00000658-193312000-00002

5. Willan RJ. Sarcoma and trauma. BJS (1930) 18:321-5. doi:10.1002/ bjs. 1800187014

6. Dijkstra MD, Balm AJ, Gregor RT, Hilgers FJ, Loftus BM. Soft tissue sarcomas of the head and neck associated with surgical trauma. J Laryngol Otol (1995) 109(2):126-9. doi:10.1017/S0022215100129457

7. Camboni M, Hammond S, Martin LT, Martin PT. Induction of a regenerative microenvironment in skeletal muscle is sufficient to induce embryonal rhabdomyosarcoma in p53-deficient mice. JPathol (2012) 226(1):40-9. doi:10.1002/path.2996

8. Van Mater D, Añó L, Blum JM, Webster MT, Huang W, Williams N, et al. Acute tissue injury activates satellite cells and promotes sarcoma formation via the HGF/c-MET signaling pathway. Cancer Res (2015) 75(3):605-14. doi:10.1158/0008-5472.CAN-14-2527

9. Dolberg DS, Hollingsworth R, Hertle M, Bissell MJ. Wounding and its role in RSV-mediated tumor formation. Science (1985) 230(4726):676-8. doi:10.1126/science.2996144

10. Sieweke MH, Thompson NL, Sporn MB, Bissell MJ. Mediation of woundrelated Rous sarcoma virus tumorigenesis by TGF-beta. Science (1990) 248(4963):1656-60. doi:10.1126/science.2163544

11. Martins-Green M, Boudreau N, Bissell MJ. Inflammation is responsible for the development of wound-induced tumors in chickens infected with Rous sarcoma virus. Cancer Res (1994) 54(16):4334-41.

12. Schuh AC, Keating SJ, Monteclaro FS, Vogt PK, Breitman ML. Obligatory wounding requirement for tumorigenesis in v-jun transgenic mice. Nature (1990) 346(6286):756-60. doi:10.1038/346756a0

13. Schuh AC, Keating SJ, Yeung MC, Breitman ML. Skeletal muscle arises as a late event during development of wound sarcomas in v-jun transgenic mice. Oncogene (1992) 7(4):667-76.

14. Shalaby F, Schuh AC, Breitman ML. Two distinct target cells for v-jun mediated wound tumorigenesis. Oncogene (1994) 9(9):2579-88.

15. Yang X, La Rosa FG, Genova EE, Huber K, Schaack J, Degregori J, et al. Simultaneous activation of Kras and inactivation of p53 induces soft tissue sarcoma and bladder urothelial hyperplasia. PLoS One (2013) 8(9):e74809. doi:10.1371/journal.pone.0074809

16. Balkwill F, Mantovani A. Inflammation and cancer: back to Virchow? Lancet (2001) 357(9255):539-45. doi:10.1016/S0140-6736(00)04046-0

17. Coussens LM, Werb Z. Inflammation and cancer. Nature (2002) 420(6917): 860-7. doi:10.1038/nature01322

18. Lu H, Ouyang W, Huang C. Inflammation, a key event in cancer development. Mol Cancer Res (2006) 4(4):221-33. doi:10.1158/1541-7786.MCR-05-0261

19. Philip M, Rowley DA, Schreiber H. Inflammation as a tumor promoter in cancer induction. Semin Cancer Biol (2004) 14(6):433-9. doi:10.1016/j. semcancer.2004.06.006
20. Werner S, Grose R. Regulation of wound healing by growth factors and cytokines. Physiol Rev (2003) 83(3):835-70.

21. Eming SA, Krieg T, Davidson JM. Inflammation in wound repair: molecular and cellular mechanisms. J Invest Dermatol (2007) 127(3):514-25. doi:10.1038/ sj.jid. 5700701

22. Radons J. Inflammatory stress and sarcomagenesis: a vicious interplay. Cell Stress Chaperones (2014) 19(1):1-13. doi:10.1007/s12192-013-0449-4

23. Henderson TO, Whitton J, Stovall M, Mertens AC, Mitby P, Friedman D, et al. Secondary sarcomas in childhood cancer survivors: a report from the childhood cancer survivor study. J Natl Cancer Inst (2007) 99(4):300-8. doi:10.1093/jnci/djk052

24. Huang J, Mackillop WJ. Increased risk of soft tissue sarcoma after radiotherapy in women with breast carcinoma. Cancer (2001) 92(1):172-80. doi:10.1002/1097-0142(20010701)92:1<172::AID-CNCR1306>3.0.CO;2-K

25. Kirova YM, Gambotti L, De Rycke Y, Vilcoq JR, Asselain B, Fourquet A. Risk of second malignancies after adjuvant radiotherapy for breast cancer: a large-scale, single-institution review. Int J Radiat Oncol Biol Phys (2007) 68(2):359-63. doi:10.1016/j.ijrobp.2006.12.011

26. Travis LB, Fosså SD, Schonfeld SJ, McMaster ML, Lynch CF, Storm H, et al. Second cancers among 40,576 testicular cancer patients: focus on longterm survivors. J Natl Cancer Inst (2005) 97(18):1354-65. doi:10.1093/ jnci/dji278

27. Gladdy RA, Qin LX, Moraco N, Edgar MA, Antonescu CR, Alektiar KM, et al. Do radiation-associated soft tissue sarcomas have the same prognosis as sporadic soft tissue sarcomas? J Clin Oncol (2010) 28(12):2064-9. doi:10.1200/ JCO.2009.25.1728

28. Singer S, Tap WD, Crago AM, O'Sullivan B. Soft tissue sarcoma. 10th ed. DeVita, Hellman, and Rosenberg's Cancer: Principles and Practice of Oncology. Wolters Kluwer Health (2015). p. 1253-91.

29. Hahn FF, Guilmette RA, Hoover MD. Implanted depleted uranium fragments cause soft tissue sarcomas in the muscles of rats. Environ Health Perspect (2002) 110(1):51-9. doi:10.1289/ehp.0211051

30. Emond CA, Vergara VB, Lombardini ED, Mog SR, Kalinich JF. Induction of rhabdomyosarcoma by embedded military-grade tungsten/nickel/cobalt not by tungsten/nickel/iron in the B6C3F1 mouse. Int J Toxicol (2015) 34(1):44-54. doi:10.1177/1091581814565038

31. Kalinich JF, Emond CA, Dalton TK, Mog SR, Coleman GD, Kordell JE, et al. Embedded weapons-grade tungsten alloy shrapnel rapidly induces metastatic high-grade rhabdomyosarcomas in F344 rats. Environ Health Perspect (2005) 113(6):729-34. doi:10.1289/ehp.7791

32. Schuster BE, Roszell LE, Murr LE, Ramirez DA, Demaree JD, Klotz BR, et al. In vivo corrosion, tumor outcome, and microarray gene expression for two types of muscle-implanted tungsten alloys. Toxicol Appl Pharmacol (2012) 265(1):128-38. doi:10.1016/j.taap.2012.08.025

Conflict of Interest Statement: The authors declare that the research was conducted in the absence of any commercial or financial relationships that could be construed as a potential conflict of interest.

Copyright (C) 2017 Bar and Merimsky. This is an open-access article distributed under the terms of the Creative Commons Attribution License (CC BY). The use, distribution or reproduction in other forums is permitted, provided the original author(s) or licensor are credited and that the original publication in this journal is cited, in accordance with accepted academic practice. No use, distribution or reproduction is permitted which does not comply with these terms. 